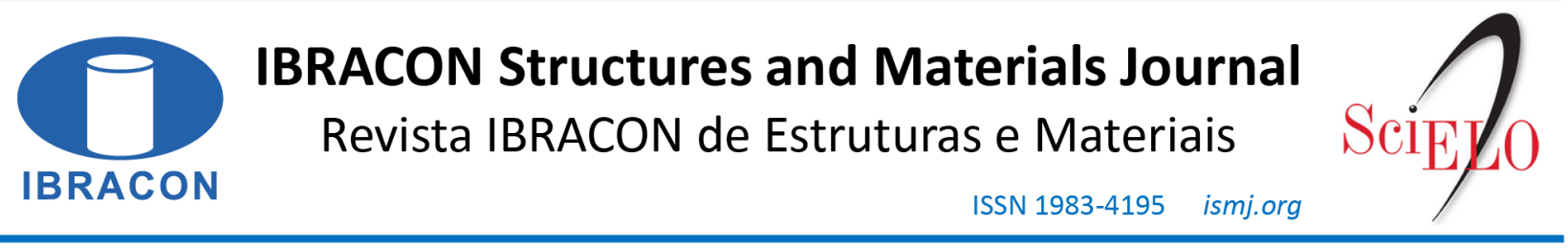

ORIGINAL ARTICLE

\title{
Analysis of the effect of the secondary moment on curved beams of full cross section
}

\section{Análise do efeito do hiperestático de protensão em vigas curvas de seções transversais maciças}

Thiago Cunha da Silva ${ }^{\mathrm{a}}$ (D)

Emil de Souza Sánchez Filho ${ }^{\mathrm{a}}$

${ }^{a}$ Universidade Federal Fluminense - UFF, Programa de Pós-graduação em Engenharia Civil, Niterói, RJ, Brasil

Received 10 July 2018

Accepted 01 July 2020

\begin{abstract}
This paper analysis the effect of the secondary moment on curved beams using the equivalent nodal loads method. A case study was carried out applying the equivalent nodal loads method to a two-span prestressed curved beam, using a curved finite element as the structural model, analyzing the effect of the secondary moment for each case and comparing it with its equivalent in straight beam. It was found that the stiffness parameters $\boldsymbol{E} \boldsymbol{I}$ and $\boldsymbol{G} \boldsymbol{J}$ influence the secondary moment. The results demonstrates that the beam opening angle reduces the effect of secondary moment, and that the greater the angle, the greater is the reduction that occurs in its secondary moment compared to its equivalent straight beam.
\end{abstract}

Keywords: prestressed concrete, secondary moment, continuous beam, curved beam, curved finite element.

\begin{abstract}
Resumo: Neste artigo estuda-se o efeito do hiperestático de protensão em vigas curvas, por meio do método das cargas nodais equivalentes. É realizado um estudo de caso, aplicando-se o método das cargas nodais equivalentes em uma viga curva protendida de dois vãos, utilizando-se como modelo estrutural um elemento finito curvo, analisando-se o efeito do hiperestático de protensão para cada caso e comparando-o com o seu equivalente em viga reta. Constatou-se analiticamente que os parâmetros de rigidez $\boldsymbol{E} \boldsymbol{I}$ e $\boldsymbol{G} \boldsymbol{J}$ influenciam na obtenção do hiperestático de protensão. Os resultados demonstram que o ângulo de abertura da viga reduz o efeito do hiperestático de protensão e que, quanto maior esse ângulo, maior é a redução que ocorre em seu hiperestático de protensão em comparação ao seu equivalente em viga reta.
\end{abstract}

Palavras-chave: concreto protendido, hiperestático de protensão, viga contínua, viga curva, elemento finito curvo.

How to cite: T. C. Silva and E. S. Sánchez Filho, "Analysis of the effect of the secondary moment on curved beams of full cross section," Rev. IBRACON Estrut. Mater., vol. 14, no. 2, e14207, 2021, https://doi.org/10.1590/S1983-41952021000200007

\section{INTRODUCTION}

Prestressed concrete has increasingly become the solution for the design of certain structures. Its use is due to the great structural advantages obtained, managing to overcome large spans, reduce the dead weight of the structures, and lower the cost of foundations.

One of the most frequent uses in prestressed concrete is in slabs and bridge beams, as the geometry of bridges often requires curved sections that make it difficult to design, considering that curved elements have peculiar characteristics that complicate structural analysis. However, the study of prestressed concrete in curved beams is still little known in scientific and academic environment, especially in the case of statically indeterminate structures. Among the tests performed on curved prestressed elements, those of Zhang et al. [1], Amorn et al. [2] and Choi et al. [3] stand out. 
The calculation of prestressing in statically indeterminate structures must take into account the effect of secondary moments. Cohn and Frostig [4] found that the secondary moments is of relevant importance in the ultimate limit state, which makes it necessary to obtain its magnitude more accurately.

Some methods proposed for the determination of the secondary moment are mentioned: Kong [5] developed a method for calculating the secondary moments based on the influence line; Raju [6] presents the usual way of calculating the secondary moment, using the equivalent distributed load method and the flexibility method; Cunha [7] presented a method that is based on the concept of equivalent nodal loads.

In this article, the effect of the secondary moment on statically indeterminate curved beams is studied, comparing the result with its straight beam equivalent, in addition to demonstrating the influence that the curvature of the structure has in determining the equivalent nodal loads.

\section{EQUIVALENT NODAL LOADS}

For the calculation of the secondary moment in curved beams, the concept of equivalent nodal load developed by Cunha [7] is used. The determination of equivalent nodal loads in prestressed structures is carried out similarly on to obtaining values of equivalent nodal load in the matrix analysis of structures. Soriano [8], Martha [9] and Przemieniecki [10] demonstrate how load values are obtained for external loads and charts with their respective values.

A curved prestressed element with fixed ends is considered and analyzed as a beam element, thus the flexibility method is applied to obtain the load values. Figure 1 illustrates the prestressed bar element whose layout has a generic configuration, in order to make the method applicable to any situation. The load value to be obtained is the equivalent bending moment, as torsion due to prestressing loading is disregarded.
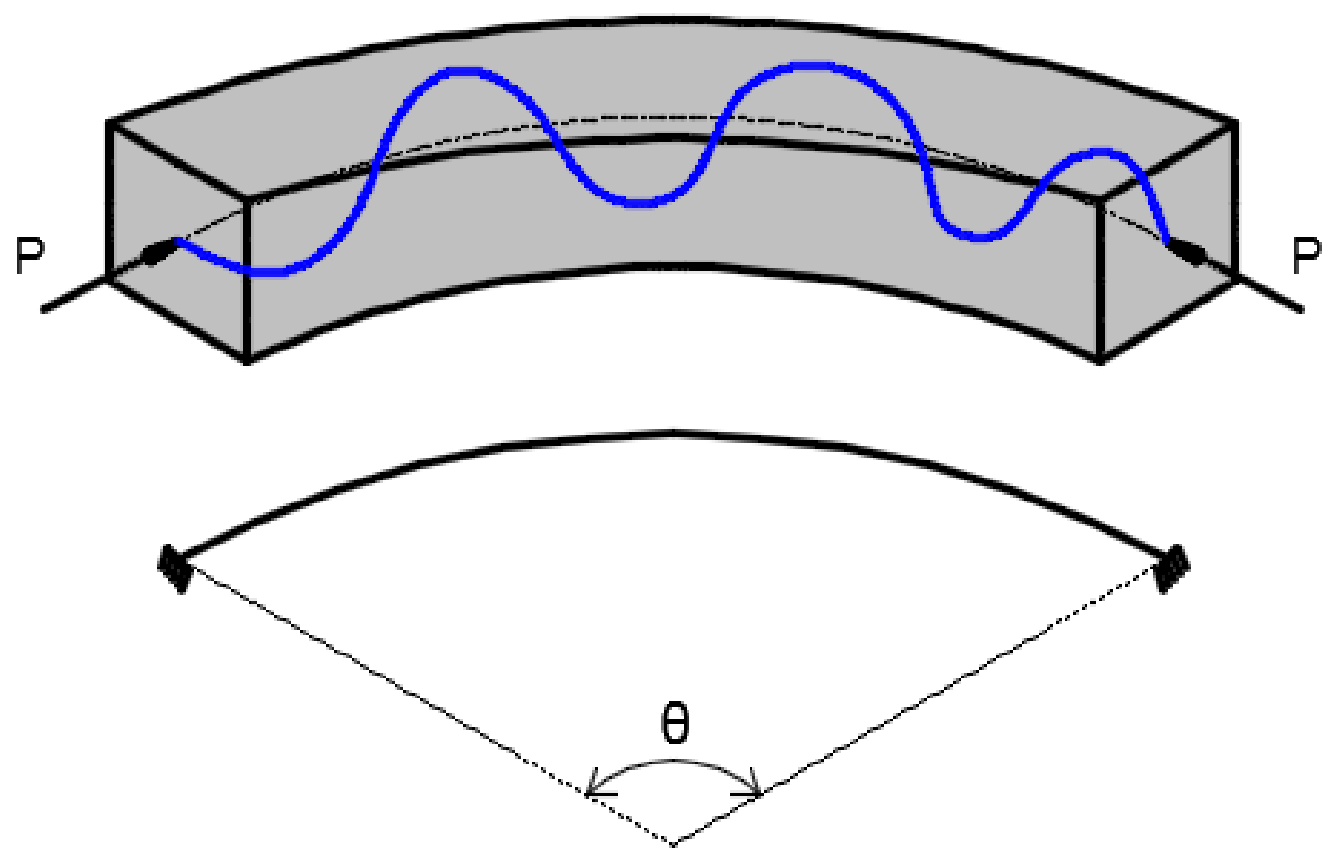

Figure 1. Curved fixed ends bar subjected to prestressing.

According to Cunha [7], the vertical reaction that appears in the fixed support should be disregarded from the calculations, because only the effect of the bending moment due to prestressing generates the secondary moment.

The deduction of equivalent nodal loads is obtained through the flexibility method (Figure 2). Considering that it is a curved element, when applying the unitary bending moment, the torsion moment occurs. The diagram of primary bending moment due to prestressed is given in a generic configuration, with the goal of making the method usable for any problem. In this study the warping of the section is disregarded. 


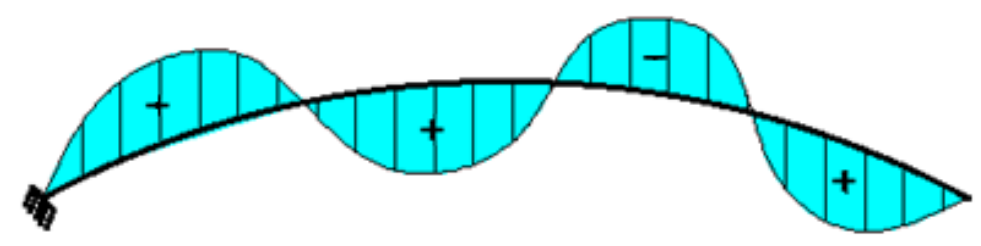

Primary bending moment diagram due to prestress

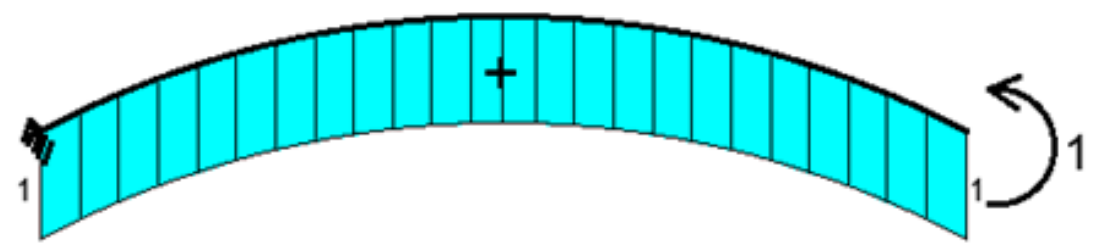

Bending moment diagram due to virtual load

Figure 2. Application of the flexibility method for obtaining equivalent nodal loads.

Figure 3 shows a differential curved bar element used as a reference for deducting the differential equations of equilibrium, where the elements of higher order are neglected. The deduction of all differential equations of equilibrium for curved beam is presented in detail in Cunha [7] and Montánari [11].

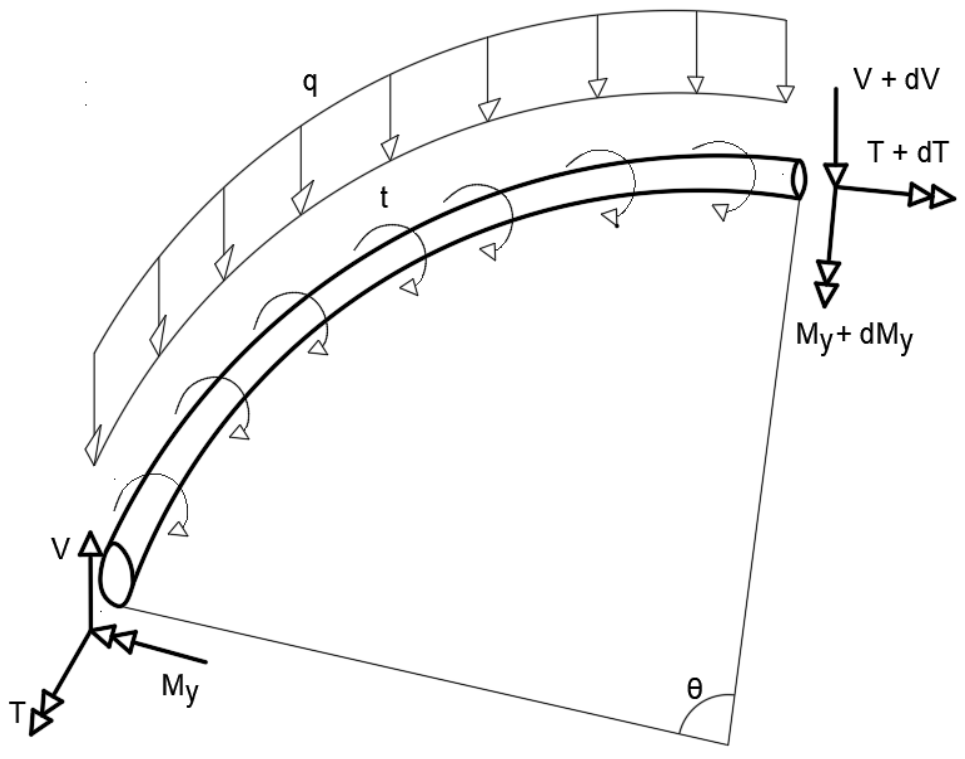

Figure 3. Differential curved bar element.

The curved beam equilibrium equation that relates the bending moment with the torsion moment can be obtained from the sum of the moments in $x$ direction (normal axis to the section of the element) and from geometric relationship $\mathrm{ds}=\mathrm{rd} \theta$, obtaining:

$\frac{\mathrm{dT}}{\mathrm{ds}}+\frac{\mathrm{M}_{\mathrm{y}}}{\mathrm{r}}=-\mathrm{t}$ 
Considering that only the effect of prestressing on the structure is studied, the external torsion loading is null, so $\mathrm{t}=0$, thus:

$\frac{\mathrm{dT}}{\mathrm{ds}}+\frac{\mathrm{M}_{\mathrm{y}}}{\mathrm{r}}=0$

The bending moment is unitary and constant along the structure (Figure 2). Replacing its value and integrating it into Equation 2, the torsion moment acting on the structure is obtained due to virtual unitary load.

$\mathrm{T}_{1}=-\frac{\mathrm{L}}{\mathrm{r}}$

Equations 5 and 6 depict the flexibility coefficients of the flexibility method

$\Delta_{11}=\int_{0}^{1} \frac{\mathrm{T}_{1}^{2}}{\mathrm{GJ}} \mathrm{ds}+\int_{0}^{1} \frac{\mathrm{M}_{1}^{2}}{\mathrm{EI}} \mathrm{ds}$

$\Delta_{11}=\frac{\mathrm{L}^{3}}{\mathrm{r}^{2} \mathrm{GJ}}+\frac{\mathrm{L}}{\mathrm{EI}}$

$\Delta_{10}=\int_{0}^{\mathrm{L}} \frac{\mathrm{m} \overline{\mathrm{m}}}{\mathrm{EI}}=\frac{\int_{0}^{\mathrm{L}} \mathrm{Pz}(\mathrm{s}) \mathrm{ds}}{\mathrm{EI}}$

that gathered in the compatibility equation

$\Delta_{10}+\mathrm{x}_{1} \Delta_{11}=0$

$\left(\frac{\mathrm{L}^{3}}{\mathrm{r}^{2} \mathrm{GJ}}+\frac{\mathrm{L}}{\mathrm{EI}}\right) \mathrm{x}_{1}+\int_{0}^{1} \mathrm{Pz}(\mathrm{s}) 1 \frac{\mathrm{ds}}{\mathrm{EI}}=0$

Results in

$\mathrm{x}_{1}=-\frac{\mathrm{r}^{2} \mathrm{GJ}}{\mathrm{L}\left(\mathrm{L}^{2} \mathrm{EI}+\mathrm{r}^{2} \mathrm{GJ}\right)} \int_{0}^{\mathrm{L}} \mathrm{Pz}(\mathrm{s}) \mathrm{ds}$

In equation 9 using the following notation we have

$\mu=\frac{r^{2} G J}{\left(L^{2} E I+r^{2} G J\right)}$

where $\mathrm{m}=$ bending moment due to prestressing; $\overline{\mathrm{m}}=$ bending moment due to unit load; $\mathrm{P}=$ prestressing force applied; L = span length; $\mathrm{r}=$ beam radius of curvature; EI = span flexural stiffness; GJ = span torsional rigidity; $\Delta_{10}=$ displacement at point 1 due to the load applied at point $0 ; \Delta_{11}=$ displacement at point 1 due to unit load at point $1 ; \mathrm{z}(\mathrm{s})=$ height of the prestressing cable. 
The value $\mu$ shown in Equation 10 is called by Cunha [7] as a reduction factor due to curvature. Thus, the equivalent nodal load is given by

$\mathrm{M}_{1}=-\mu \frac{\int_{0}^{\mathrm{L}} \mathrm{Pz}(\mathrm{s}) \mathrm{ds}}{\mathrm{L}}$

Equation 11 is valid only when the prestressing force is centered, that is, when there is no resulting eccentricity in the section that generates torsion. If there is an eccentricity, the effect of torsion due to prestressing should be considered in determining the load values.

Figure 4 shows the equivalent nodal loads due to prestressing for fixed ends situation.

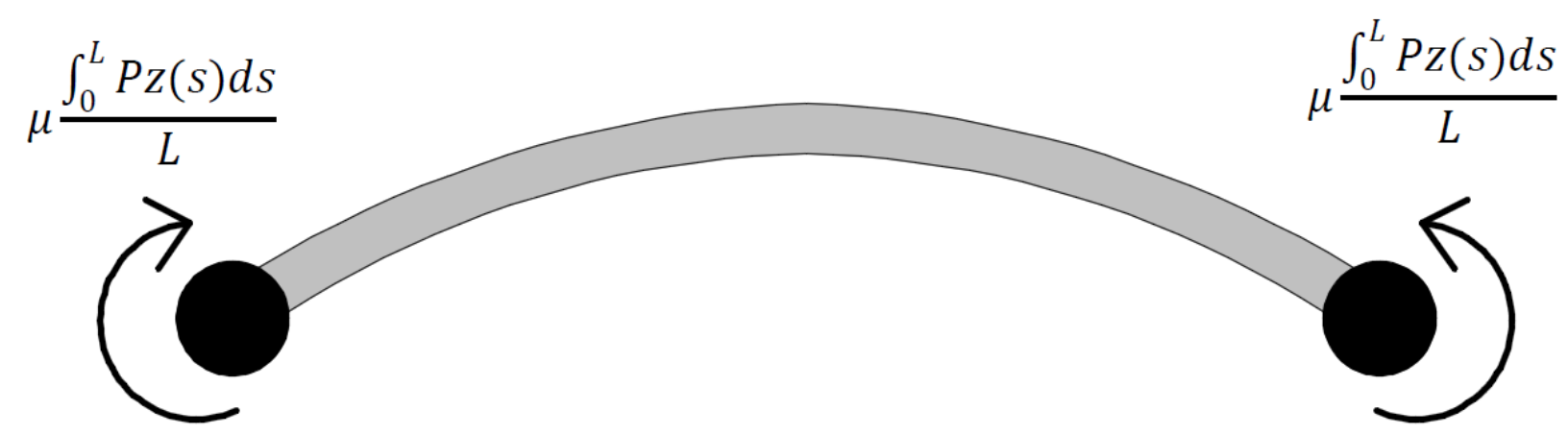

Figure 4. Prestressing equivalent nodal load.

The orientation of the nodal load is a function of the $\int_{0}^{\mathrm{L}} \mathrm{Pz}(\mathrm{s}) \mathrm{ds}$ portion, which, if positive, the orientation is the same as shown in Figure 4. If on the contrary, the orientation goes in the opposite direction.

The $\int_{0}^{\mathrm{L}} \mathrm{z}(\mathrm{s}) \mathrm{ds}$ portion is the area between the centroid of the section and the prestressing profile along its entire length. The strategy for using this method consists of dividing the beam into sections, calculating the area between the prestressing profile and the centroid in each section and multiplying it by the average prestressing force of the section, considering prestressing losses.

It is observed that the equivalent nodal load is presented as a parameter to assess the influence that the secondary moment has on the structure. As this is the calculation of the area between the centroid of the section and the profile, if the sum of the areas is null, the secondary moment does not occur, Raju [6] defines this characteristic as a concordant prestressing path.

\section{STIFFNESS MATRIX OF CURVED FINITE ELEMENT}

The stiffness matrix of a curved element of constant section and curvature to be used was deduced by Palaninathan and Chandrasekharan [12], based on Lee's studies [13]. The original element has six degrees of freedom per node (Figure 5). 


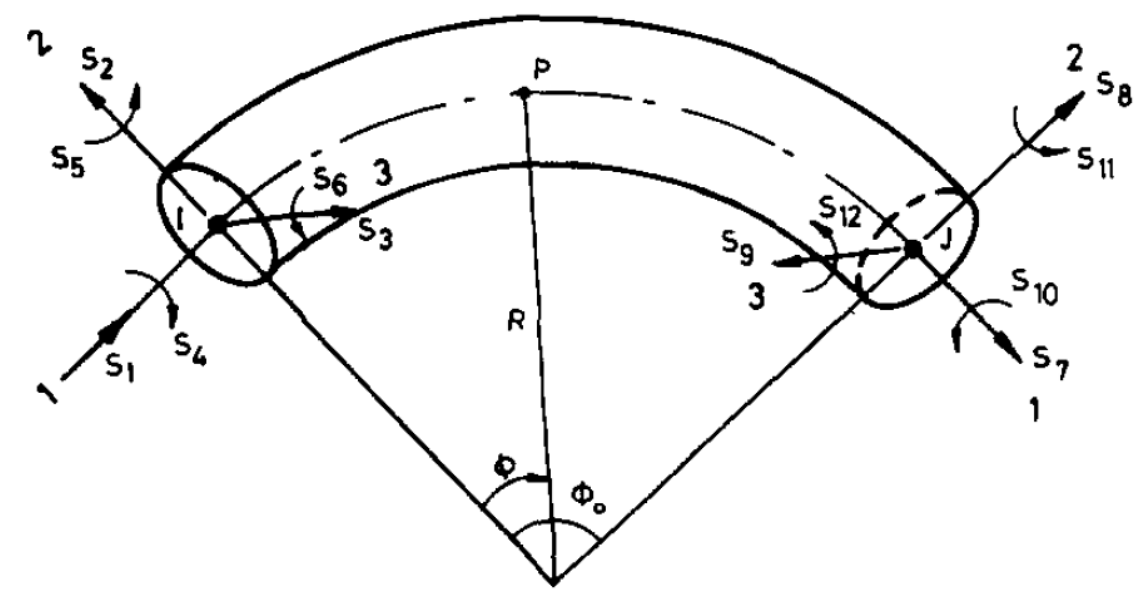

Figure 5. Curved beam element, Palaninathan and Chandrasekharan [12].

However, the number of degrees of freedom was reduced to three, being the vertical force, the bending moment and the torsion moment, transforming it into a curved grid finite element (Figure 6).

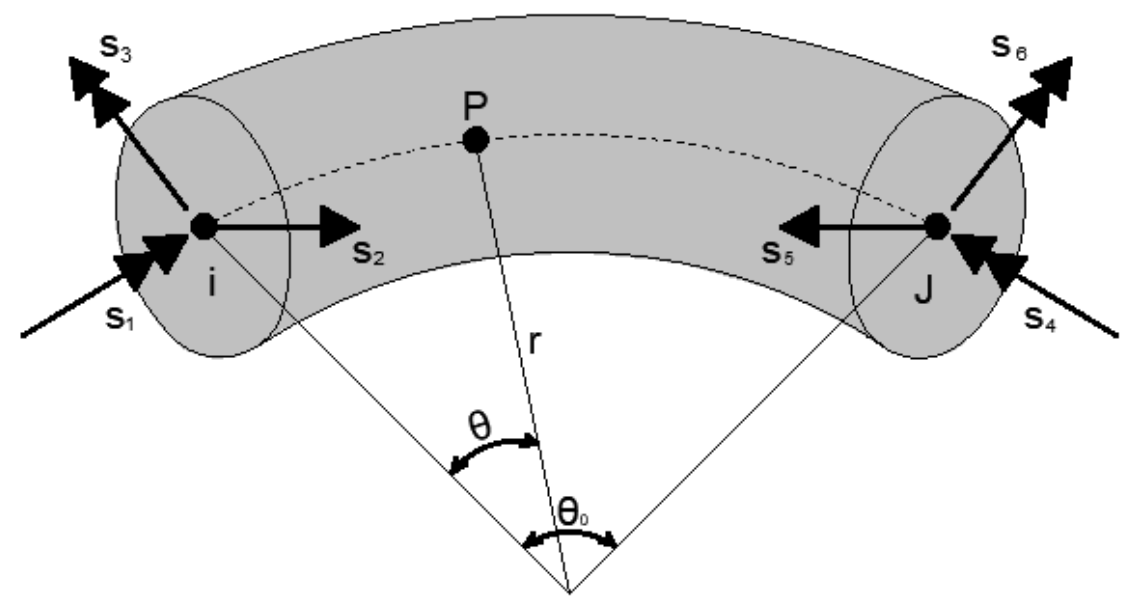

Figure 6. Curved grid finite element.

The reduction in the number of degrees of freedom aims at simplifying the structural calculation, since the inversion of the $12 \times 12$ stiffness matrix would result in a large computational work, in addition to the other variables involved.

The internal forces and the moments acting at point $\mathrm{P}$ are expressed in values of the forces from node $\mathrm{i}$ as follows

$\mathrm{V}^{\prime}=\mathrm{V}_{2}$

$\mathrm{T}^{\prime}=\mathrm{T}_{1} \cos (\varnothing)-\mathrm{M}_{3} \operatorname{sen}(\varnothing)-\mathrm{V}_{2} \mathrm{r}(1-\cos (\varnothing))$

$\mathrm{M}^{\prime}=\mathrm{T}_{1} \operatorname{sen}(\varnothing)+\mathrm{M}_{3} \cos (\varnothing)+\mathrm{V}_{2} \mathrm{rsen}(\varnothing)$

The strain energy in the element, disregarding the section warping effect, is given by 
$\mathrm{U}=\frac{\mathrm{r}}{2} \int_{0}^{\varnothing}\left(\frac{\mathrm{T}^{\prime 2}}{\mathrm{GJ}}+\frac{\mathrm{M}^{\prime 2}}{\mathrm{EI}}\right) \mathrm{d} \varnothing$

Using Castigliano's theorem we obtain

$\mathrm{U}_{1}=\frac{\partial \mathrm{U}}{\partial \mathrm{T}^{\prime}}=\frac{\mathrm{r}}{\mathrm{GJ}} \int_{0}^{\varnothing} \mathrm{T}^{\prime} \frac{\partial \mathrm{T}^{\prime}}{\partial \mathrm{T}^{\prime}} \mathrm{d} \varnothing+\frac{\mathrm{r}}{\mathrm{EI}} \int_{0}^{\varnothing} \mathrm{M}^{\prime} \frac{\partial \mathrm{M}^{\prime}}{\partial \mathrm{T}^{\prime}} \mathrm{d} \varnothing$

$\mathrm{U}_{2}=\frac{\partial \mathrm{U}}{\partial \mathrm{V}^{\prime}}=\frac{\mathrm{r}}{\mathrm{GJ}} \int_{0}^{\varnothing} \mathrm{T}^{\prime} \frac{\partial \mathrm{T}^{\prime}}{\partial \mathrm{V}^{\prime}} \mathrm{d} \varnothing+\frac{\mathrm{r}}{\mathrm{EI}} \int_{0}^{\varnothing} \mathrm{M}^{\prime} \frac{\partial \mathrm{M}^{\prime}}{\partial \mathrm{V}^{\prime}} \mathrm{d} \varnothing$

$\mathrm{U}_{3}=\frac{\partial \mathrm{U}}{\partial \mathrm{M}^{\prime}}=\frac{\mathrm{r}}{\mathrm{GJ}} \int_{0}^{\varnothing} \mathrm{T}^{\prime} \frac{\partial \mathrm{T}^{\prime}}{\partial \mathrm{M}^{\prime}} \mathrm{d} \varnothing+\frac{\mathrm{r}}{\mathrm{EI}} \int_{0}^{\varnothing} \mathrm{M}^{\prime} \frac{\partial \mathrm{M}^{\prime}}{\partial \mathrm{M}^{\prime}} \mathrm{d} \varnothing$

Developing the integrals and applying Castigliano's theorem we have the following system of equations

$$
\left(\begin{array}{l}
u_{1} \\
u_{2} \\
u_{3}
\end{array}\right)=\left(\begin{array}{lll}
a_{11} & a_{12} & a_{13} \\
a_{12} & a_{22} & a_{23} \\
a_{13} & a_{23} & a_{33}
\end{array}\right)\left(\begin{array}{c}
\mathrm{V}^{\prime} \\
T^{\prime} \\
M^{\prime}
\end{array}\right)
$$

By developing the integral of the strain energy and using the following equation to simplify the values obtained, results

$\lambda=\frac{\mathrm{EI}}{\mathrm{GJ}}$

$\Delta_{\mathrm{AA}}=\frac{1}{\mathrm{EI}}\left(\begin{array}{lll}\frac{\mathrm{r}^{2}}{2}(\lambda \mathrm{Cr}+\mathrm{Br}) & \frac{\mathrm{r}^{2}}{2}(\mathrm{~B}-\lambda \mathrm{V}) & \frac{\mathrm{r}^{2}}{2}(\lambda \mathrm{S}-\mathrm{D}) \\ \frac{\mathrm{r}^{2}}{2}(\mathrm{~B}-\lambda \mathrm{V}) & \frac{\mathrm{r}}{2}(\lambda \mathrm{N}+\mathrm{B}) & \frac{\mathrm{r}}{2}(\lambda \mathrm{D}-\mathrm{D}) \\ \frac{\mathrm{r}^{2}}{2}(\lambda \mathrm{S}-\mathrm{D}) & \frac{\mathrm{r}}{2}(\lambda \mathrm{D}-\mathrm{D}) & \frac{\mathrm{r}}{2}(\lambda \mathrm{B}+\mathrm{N})\end{array}\right)$

Where

$\mathrm{N}=\theta+\frac{\operatorname{sen}(2 \theta)}{2}$

$\mathrm{B}=\theta-\frac{\operatorname{sen}(2 \theta)}{\theta}$

$\mathrm{C}=3 \theta+\frac{\operatorname{sen}(2 \theta)}{\theta}-4 \operatorname{sen}(\theta)$

$\mathrm{S}=\frac{3}{4}-\cos (\theta)+\frac{\cos (2 \theta)}{4}$ 
$\mathrm{V}=2 \operatorname{sen}(\theta)-\theta-\frac{\operatorname{sen}(2 \theta)}{2}$

$\mathrm{D}=\frac{\cos (2 \theta)}{2}-\frac{1}{2}$

The stiffness matrix of the element is given by the joining of matrices $\mathrm{K}_{\mathrm{AA}}, \mathrm{K}_{\mathrm{AB}}, \mathrm{K}_{\mathrm{BA}} \mathrm{e} \mathrm{K}_{\mathrm{BB}}$, thus

$\mathrm{k}=\left[\begin{array}{ll}\mathrm{K}_{\mathrm{AA}} & \mathrm{K}_{\mathrm{AB}} \\ \mathrm{K}_{\mathrm{BA}} & \mathrm{K}_{\mathrm{BB}}\end{array}\right]$

The $\mathrm{K}_{\mathrm{AA}}$ matrix is obtained by inverting the flexibility matrix $\Delta_{\mathrm{AA}}$

$\mathrm{K}_{\mathrm{AA}}=\Delta_{\mathrm{AA}}{ }^{-1}$

The matrix $\mathrm{T}$ relates the forces of the final node $\mathrm{j}$ to the forces of the initial node $\mathrm{i}$

$$
\mathrm{T}=\left[\begin{array}{ccc}
-1 & 0 & 0 \\
\mathrm{r}(1-\cos (\theta)) & -\cos (\theta) & \operatorname{sen}(\theta) \\
\operatorname{rsen}(\theta) & -\operatorname{sen}(\theta) & -\cos (\theta)
\end{array}\right]
$$

The $\mathrm{K}_{\mathrm{BA}}$ matrix is obtained by

$\mathrm{K}_{\mathrm{BA}}=\mathrm{TK}_{\mathrm{AA}}$

In a similar way, the flexibility matrix is obtained

$$
\Delta_{\mathrm{BB}}=\frac{1}{\mathrm{EI}}\left(\begin{array}{ccc}
\frac{\mathrm{r}^{2}}{2}(\lambda \mathrm{Cr}+\mathrm{Br}) & \frac{\mathrm{r}^{2}}{2}(\mathrm{~B}-\lambda \mathrm{V}) & -\frac{\mathrm{r}^{2}}{2}(\lambda \mathrm{S}-\mathrm{D}) \\
\frac{\mathrm{r}^{2}}{2}(\mathrm{~B}-\lambda \mathrm{V}) & \frac{\mathrm{r}}{2}(\lambda \mathrm{N}+\mathrm{B}) & -\frac{\mathrm{r}}{2}(\lambda \mathrm{D}-\mathrm{D}) \\
-\frac{\mathrm{r}^{2}}{2}(\lambda \mathrm{S}-\mathrm{D}) & -\frac{\mathrm{r}}{2}(\lambda \mathrm{D}-\mathrm{D}) & \frac{\mathrm{r}}{2}(\lambda \mathrm{B}+\mathrm{N})
\end{array}\right)
$$

The $\mathrm{K}_{\mathrm{BB}}$ matrix is obtained by inverting the flexibility matrix

$$
\mathrm{K}_{\mathrm{BB}}=\Delta_{\mathrm{BB}}^{-1}
$$

being that

$\mathrm{K}_{\mathrm{AB}}=\mathrm{TK}_{\mathrm{BB}}$

With this data, the stiffness matrix of the element can be assembled. 


\section{NUMERICAL EXAMPLE}

The effect of the secondary moment on a continuous beam with two spans of constant curvature is studied and the results are compared with straight continuous beam of length equivalent to the radius and angle adopted in each case. The support conditions for both beams are of restriction to vertical and horizontal reaction. The study is carried out on a beam with a radius of $40 \mathrm{~m}$, varying its angle from $10^{\circ}$ to $10^{\circ}$ increments, up to $90^{\circ}$.

Mathcad software was used to calculate the example, basing its implementation routine on studies carried out by Vaz [14] and Soriano [8], using as a basis the matrix analysis of structures and the finite element method.

In order to simplify the study of the effect of the secondary moment on curved beams, it is settled that, in all cases, the lengths of the spans are equal, thus, $\mathrm{L}_{1}=\mathrm{L}_{2}$.

The prestressing path is straight with an applied load of $1000 \mathrm{kN}$. In order to facilitate the study, a constant prestressing loss of $20 \%$ was also admitted along its entire path and its eccentricity e $=40 \mathrm{~cm}$. The portion corresponding to the prestressing of the equivalent nodal load (Equation 11) is the following value.

$\frac{\int_{0}^{\mathrm{L}_{1}} \mathrm{Pz}(\mathrm{s}) \mathrm{ds}}{\mathrm{L}_{1}}=\frac{\int_{0}^{\mathrm{L}_{2}} \mathrm{Pz}(\mathrm{s}) \mathrm{ds}}{\mathrm{L}_{2}}=800 \times 0.4=320 \mathrm{kN} \cdot \mathrm{m}$

Equation 35 is constant in all cases, since there is no change in the eccentricity or in load path profile. However, the equivalent nodal load (Equation 11) changes in all cases as a function of the reduction factor due to the curvature $\mu$.

The modified curved finite element of Palaninathan and Chandrasekharan [10] was used for the calculation of the curved beam and for the straight beam the bar element.

\section{Two span continuous curved beam}

Figure 7 shows the section data.

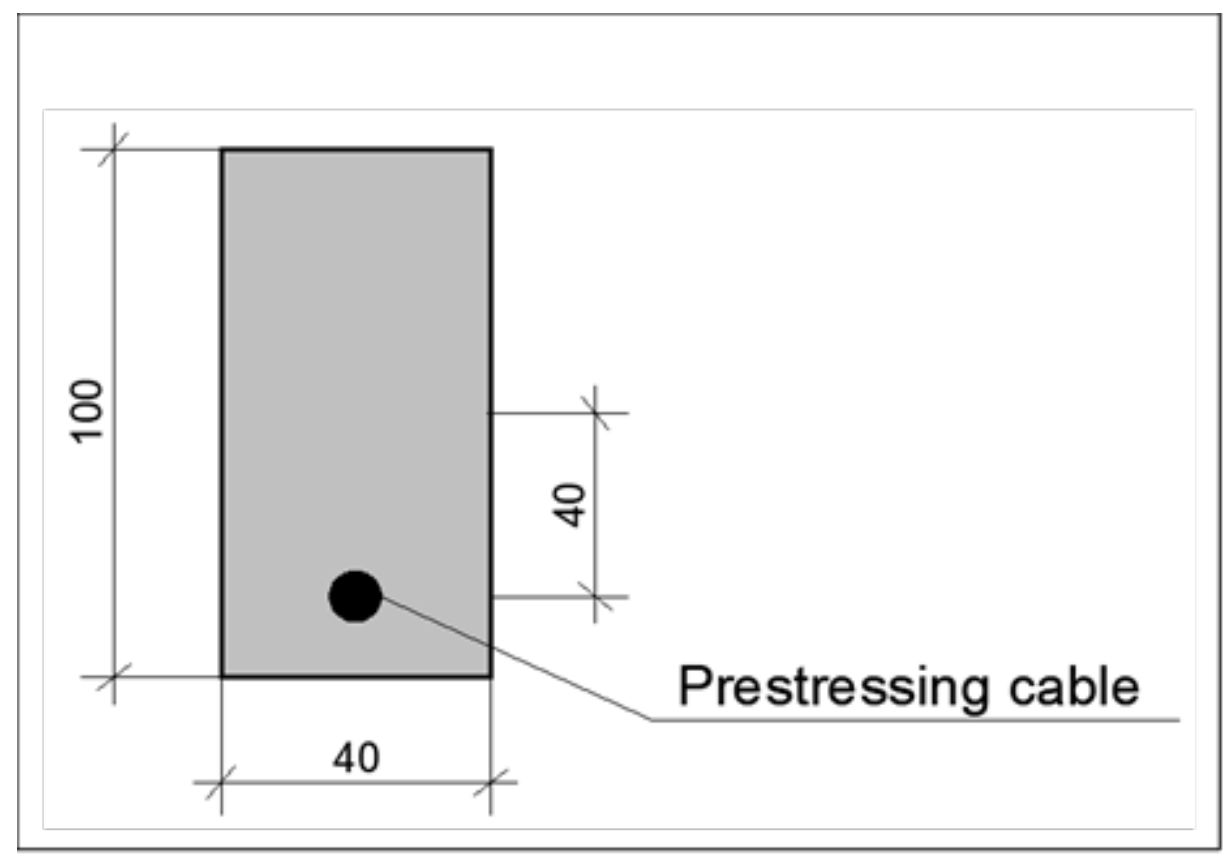

Figure 7. Prestressed cross section, measured in $\mathrm{cm}$.

The ratio between flexural stiffness and torsional stiffness is equal to 1 for all cases presented.

The boundary conditions adopted in the structure are shown in Figure 8, which are the restriction to vertical displacement in all nodes of the structure. 


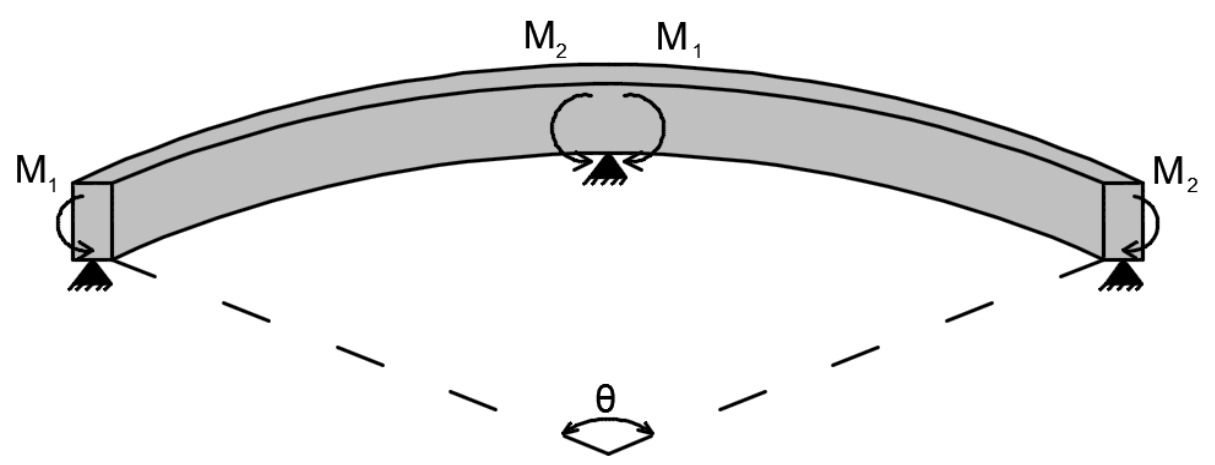

Figure 8. Two-span curved continuous beam.

Table 1 presents the results obtained in each case and Figure 9 shows, in a generic way, the effect of the secondary moment in the curved beam.

Table 1. Two-span curved continuous beam subjected to centered prestressing $(r=40 \mathrm{~m})$.

\begin{tabular}{cccccc}
\hline Radius (m) & $\mathbf{4 0}$ & \multicolumn{5}{c}{$\boldsymbol{\lambda = \mathbf { 1 }}$} \\
\cline { 6 - 7 } $\begin{array}{c}\text { Angle } \\
\text { (Degrees) }\end{array}$ & $\boldsymbol{\mu}$ & $\begin{array}{c}\text { Redundant Reaction } \\
\text { (kN) (Curved Beam) }\end{array}$ & $\begin{array}{c}\text { Equivalent Span } \\
\text { Length (m) }\end{array}$ & $\begin{array}{c}\text { Redundant Reaction } \\
\text { (kN) (Straight Beam) }\end{array}$ & $\begin{array}{c}\text { Ratio (Curved / } \\
\text { Straight) }\end{array}$ \\
\hline 10 & 0.99 & 272.70 & 3.49 & 275.02 & $99.2 \%$ \\
\hline 20 & 0.97 & 132.97 & 6.98 & 137.51 & $96.7 \%$ \\
\hline 30 & 0.94 & 85.12 & 10.47 & 91.67 & $92.8 \%$ \\
\hline 40 & 0.89 & 60.44 & 13.96 & 68.75 & $87.9 \%$ \\
\hline 50 & 0.84 & 45.22 & 17.45 & 55.00 & $82.2 \%$ \\
\hline 60 & 0.78 & 34.89 & 20.94 & 45.84 & $76.1 \%$ \\
\hline 70 & 0.73 & 27.49 & 24.43 & 39.29 & $70.0 \%$ \\
\hline 80 & 0.67 & 21.95 & 27.93 & 34.38 & $63.8 \%$ \\
\hline 90 & 0.62 & 17.75 & 31.42 & 30.56 & $58.1 \%$ \\
\hline
\end{tabular}

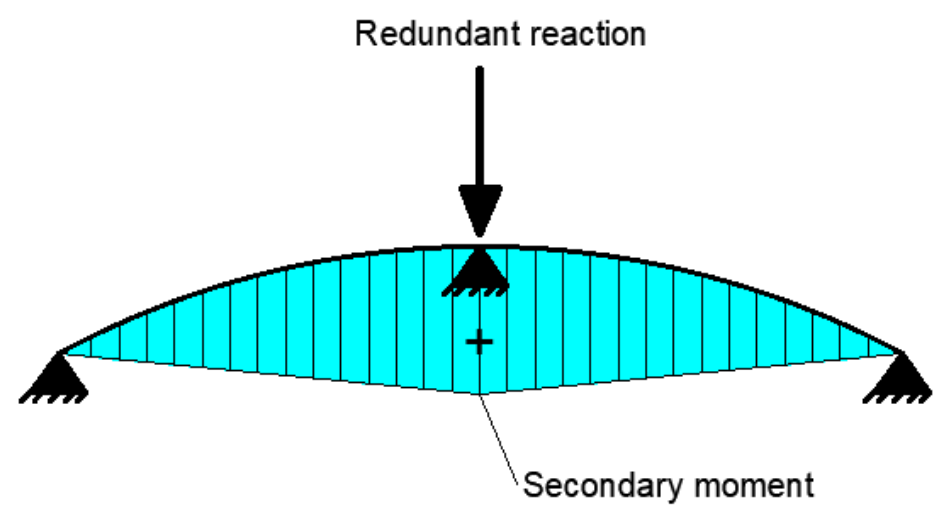

Figure 9. Effect of the secondary moment in curved beam.

\section{ANALYSIS OF RESULTS}

It is assessed that the secondary moment in a curved structure has its value reduced as function of the beam opening angle. For small opening angles, between $10^{\circ}$ and $30^{\circ}$, the reduction that occurs in its secondary moment is insignificant, reaching a maximum of $7.2 \%$ when compared to its straight equivalent beam. Garrett and Cochrane [15] 
arrived at similar analytical results, concluding that a curved beam with an opening angle of less than $30^{\circ}$ can be calculated as a straight beam with good precision of the results. Tests carried out by Amorn et al. [2] and compared by a straight beam model in Cunha [7] prove that curved beams with a small opening angle, including prestressed ones, can be approximated by a straight beam with a negligible difference in result, which corroborates the results obtained.

The radius of the structure does not influence the obtaining of factor $\mu$, as this depends directly on the opening angle of the structure and the stiffness parameters EI and GJ. The reduction factor $\mu$ has a greater influence on the structure when its opening angle increases, because the larger its opening, the greater the interaction between the bending moment and the torsion moment, as can be seen in Equation 14.

The secondary moment has its value reduced by down to approximately $42 \%\left(90^{\circ}\right.$ angle), showing that in curved structures, with a high opening angle, the secondary moment has significantly less influence than in rectilinear structures.

It should be noted that the results obtained took into account that the flexural stiffness has a numerical value equal to the torsional stiffness, it can be deduced that if $\lambda>1$, that is, the flexural stiffness is superior to the torsional stiffness, a reduction of the factor $\mu$ occurs and if $\lambda<1$ result in its increase. It should be highlighted that the stiffness parameters, in addition to being important in determining the $\mu$ factor, are also relevant in determining the coefficients of the curved finite element stiffness matrix.

It is noteworthy that this study did not take into account the distortion due to shear, as well as the effect of prestressing in thin-walled sections, whether open or closed. The results obtained are valid only for full sections, where shear has little influence on the distortion of the section.

\section{CONCLUSIONS}

In curved beams, the reduction factor due to curvature $\mu$ is the main cause of the decrease in secondary moment. It has been proven that beams with a high opening angle have a greater reduction in their secondary moment. It is worth noting that the relationship between flexural stiffness and torsional stiffness also contribute to the variation of the $\mu$ factor intensity, it was found that if the flexural stiffness is greater than the torsional stiffness it results in a reduction of the $\mu$ factor and if otherwise, it increases. Therefore, it is inferred that the main variables for the calculation of the secondary moment, in a curved beam, are the opening angle of the structure and its stiffness parameters EI and GJ.

By the method of equivalent nodal load it is verified that, in prestressed beams whose tracing is straight, the secondary moment occurs accentuated, since the area between the centroid and the prestressing cable is larger than in beams whose tracing is variable.

The results conveyed that in curved beams with a small opening angle (between $10^{\circ}$ and $30^{\circ}$ ) the difference that occurs between the secondary moment of the curved beam and its equivalent of straight beam is negligible in the centered prestressing, reaching less than $7.2 \%$, even with reduction factor applied. There is a significant decrease in secondary moment, mainly in beams whose opening angle is high.

The curved element used for the beam calculation is more complicated to be computationally implemented. While the stiffness matrix of the structure stays smaller than if discretization was used in bar elements, the number of variables involved ends up significantly impairing its computational performance.

The proximity of the results obtained, when comparing the result of straight beam with that of curved beam, allows us to consider it reasonable to discretize the structure instead of using curved elements for small opening angles, being recommended to use curved element for higher opening angles.

Ultimately, it is worth mentioning that the reduction factor must be used in curved beams whose approach has been modeled from straight bar elements. The fact that the modeling occurs with bar elements does not exempt the application of the reducing factor, which is a factor that seeks to consider the interaction between the torsion moment and the bending moment.

\section{CITATIONS}

[1] N. Zhang, C. C. Fu, and H. Che, "Experiment and numerical modeling of prestressed concrete curved slab with spatial unbonded tendons," Eng. Struct., vol. 33, no. 3, pp. 747-756, Mar 2011.

[2] W. Amorn, C. Y. Tuan, and M. K. Trados, "Curved, precast, pretensioned concrete I-girders bridges," Civ. Eng. Fac. Publ., vol. 11, no. 11 , pp. 48-66, Dec 2008.

[3] J. Choi, C. R. Woods, T. D. Hrynyk, and O. Bayrak, "Behavior of curved post-tensioned concrete structures without throughthickness reinforcement," ACI Struct. J., vol. 114, no. 114, pp. 983-994, Aug 2017. 
[4] M. Z. Cohn and Y. Frostig, "Inelastic behavior of continuous prestressed concrete beams," J. Struct. Eng., vol. 109, no. 10, pp. 22922309, Oct 1983.

[5] J. Kong, "A practical method for the calculation of secondary prestress moments," Hong Kong Inst. Eng., vol. 11, no. 4, pp. 49-52, Dec 2004.

[6] K. Raju, Prestressed Concrete, 4th ed. India: McGraw-Hill, 2013.

[7] T. Cunha, "Torsional moment analysis in prestressed curved beam," M.S. thesis, Civ. Eng. Postgrad. Program, Fluminense Fed. Univ., Rio de Janeiro, RJ, Brazil, 2018.

[8] H. L. Soriano, Análise de Estruturas - Formulação Matricial e Implementação Computacional. Rio de Janeiro: Ciência Moderna Ltda, 2005.

[9] L. F. Martha, Análise de Estruturas: Conceitos e Métodos Básicos, 1a ed. Rio de Janeiro: Elsevier, 2010.

[10] J. S. Przemieniecki, Theory of Matrix Structural Analysis. New York: McGraw-Hill, 2012.

[11] I. Montánari, “Protensão em vigas curvas,” Ph.D. dissertation, Fed. Univ. São Carlos, São Carlos, SP, Brazil, 1980.

[12] R. Palaninathan and P. S. Chandrasekharan, "Curved beam element stiffness matrix formulation," Comput. Struc., vol. 21, no. 4, pp. 663-669, 1985.

[13] H.-P. Lee, "Generalized stiffness matrix of a curved-beam element," AIAA J., vol. 7, no. 10, pp. 2043-2045, Oct 1969.

[14] L. E. Vaz, Método dos Elementos Finitos em Análise de Estruturas. Rio de Janeiro: Elsevier, 2011.

[15] R. J. Garrett and R. A. Cochrane, "The analysis of prestressed beams curved in plan with torsional restraint at the supports," Struct. Eng., vol. 48, no. 3, pp. 128-132, Mar 1970.

Author contributions: TC: writing, formal analysis, methodology; ES: writing, formal analysis, methodology.

Editors: Leandro Mouta Trautwein, José Luiz Antunes de Oliveira e Sousa, Guilherme Aris Parsekian. 